Joseph L. Chin, O.Ont., MD, FRCSC
CUA President

Cite as: Can Urol Assoc J 2013;7(5-6):159. http://dx.doi.org/10.5489/cuaj.1262

The CUA exists to promote the highest standard of urologic care for Canadians and to advance the art and science of urology.

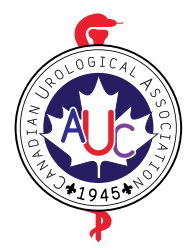

would like to briefly highlight some of the activities of the CUA in the past year, in which I have had the honour and privilege to serve as president. My term will conclude with a most spectacular and memorable Annual Meeting... more about that later. The CUA has officially adopted the very appropriate tag line of "The Voice of Urology in Canada." The Office of Education has been very active and productive, successfully mounting several programs and initiatives, with target audiences, including practicing urologists, trainees, primary care physicians, as well as patients and the public. A forum dedicated to GU cancer survivorship was very well-received. The CUA is also part of the "solution team" of the Survivorship Action Plan, an initiative sponsored by Movember and Prostate Cancer Canada. The Consumer's Handbook of Urological Health intended for the lay public has been published by the CUA and will be launched at the Annual Meeting. Furthermore, under new editorial leadership, CUAJ continues to flourish.

The CUA has also solidified relationships with several other national urologic societies, including the American Urological Association, European Association of Urology, Urological Society of Australia and New Zealand and the Chinese Urological Association. There are now formal annual exchanges of trainees and visiting professors with several of these organizations.

On behalf of CUA members, I wish to thank the Executive members, the chairs and members of all the highly functional and highly productive committees and the Corporate Office staff for their dedication to the CUA. I truly appreciate their help in rendering my job so easy. Now, onto the Annual Meeting:

Considered one of the Seven Wonders of the Modern World and with a phenomenal flow rate, Niagara Falls will be the most appropriate venue for the 68th CUA Annual Meeting. In addition to being a geologic and hydrodynamic (and urodynamic) tourist destination, Niagara Falls has something for every demographic and taste. Our Local Organizing Co-chairs, Dianne Heritz and Ian Brown, will be showcasing many of the world-class attractions. Not to be outdone, the Scientific Program Co-Chairs, Anil Kapoor and Jonathan Izawa, have organized a scientific program filled with internationally renowned speakers and informative educational fora. Furthermore, the meeting will be a great opportunity to catch up with colleagues and make new friends. The academic and social experience will be second to none. See you all then!

\section{On another note:}

"I alone cannot change the world, but I can cast a stone across the waters to create many ripples." - Mother Teresa. Dr. Beiko is hoping to change the "urology world" in CUAJ's recent editorial. It will certainly create many ripples. He has put forth a cogent argument with some compelling reasons for the name change or "re-branding" of our specialty. We have all encountered patients "who did not realize we perform surgery." We have also had medical students who were surprised that urology is a surgical specialty. As Dr. Beiko pointed out, there are parts of the world where the term "urologic surgeons" is used more commonly than "urologists." We have our own "Canadian Academy of Urological Surgeons." Other prominent examples include the "British Association of Urological Surgeons" and "American Association of Genitourinary Surgeons."

Robert Kennedy said: "Progress is a nice word. But change is its motivator. And change has its enemies." There are, indeed, numerous opponents and obstacles to such proposed monumental change with significant major downstream effects. To quote Andy Warhol: "They always say time changes things, but you actually have to change them yourself." As well, Mahatma Gandhi said "Be the change that you wish to see in the world." Personally, I support Dr. Beiko's viewpoint. The question is will CUA members want this change and join Dr. Beiko in his crusade? 